\title{
A process using ontology to automate the operationalization of pattern-based learning scenarios
}

\author{
Zeyneb Tadjine ${ }^{1}$, Lahcen Oubahssi ${ }^{1}$, Claudine Piau-Toffolon ${ }^{1}$, Sébastien Iksal ${ }^{1}$ \\ ${ }^{1}$ LUNAM University, University of Maine, EA 4023, LIUM, 72085 Le Mans, France \\ \{FirstName.LastName\}@univ-lemans.fr
}

\begin{abstract}
For most teachers-designers, operationalizing learning scenarios based on patterns just replicates traditional ways by adding course content and multimedia elements on learning management systems (LMS). We aim to go beyond this method by trying to engage the teachers-designers to design deployable learning scenarios. Using patterns for their design is proven to be an adequate solution to seek balance between the need of expressive instructional scenarios, and the technical constraints that occur while deploying these scenarios on learning management systems. Pattern's formal description is needed in order to translate the concepts of a pedagogical scenario, according to those embedded in the LMS. In this paper, we propose a process to structure, index, formalize, and finally adapt and operationalize the pattern-based learning scenarios. The presented process shows how the use of an ontology modeling learning scenario's concepts helps the automation of deploying the learning scenarios on an LMS. For that, this ontology has been extended with one representing a learning platform paradigm.
\end{abstract}

Keywords: Operationalization, Patterns, Ontologies, Instructional design, LMS, Teaching situation.

\section{Introduction}

Over the last decade we have seen the rise of learning design tools oriented learning platforms as an alternative to the classic way of designing learning scenarios. Although this initiative is very useful for both teachers and learners because it allows taking advantage of the features proposed by learning platforms, we notice that the final result of these tools is facing problems with the "full-integration" and compatibility with institutional systems [1]. We note also, that despite of the significant advances in research work about learning environments, the operationalization phase of learning scenarios still remains a challenge. Teachers-designers still need assistance during this phase. We take interest in our research work to the "full cycle" of designing, operationalizing and adapting educational situations. We consider the operationalization as the development of specific research procedures that will result in empirical observations representing the learning scenario's concepts technology enhanced learning environments. One issue that we address is related to the machine-readable 
representations of teaching practice for technology enhanced learning environments. The other, addressed to the human-readable representations for sharing design knowledge between teachers. We need to find the right balance between the expressiveness and usability of a representation form [2]. Seeking answers for these issues, we studied the importance of the semantic technology and in particular the use of ontologies in developing learning design tools. Our focus was on how ontology- driven tools can support a learning design environment for teachers-designers to create designs under their own terms, and at the same time deployable under learning management systems terms, this, with a minimum of semantic loss. And since the facility of teacher's expressiveness is one of our major concerns, we studied how using a pattern-based learning design tool could help offering deployable learning scenarios. Their formalism has to respect a well defined structure in order to map easily the concepts embedded in the resulted learning scenario with the learning platform concepts. The semi-structured representation of scenarios will enable the capitalization and the reuse of teaching practices used by teachers. Most importantly, our hypothesis is that this representation allows browsing the patterns for relevant information retrieval and the deployment of this information. The final goal is to ensure an automatic deployment of the pattern-based learning scenarios on learning management systems such as Moodle [3] and Sakai [4]. We propose a five steps process, as presented in section 4. The structuring and indexing phases provide a conceptual representation of theory and practice about learning scenarios, as well as about learning environments, and make it available for use, through a pattern-based tool for designing scenarios by teachersdesigners as a Formalizing phase. This, ensures to benefit from the learning design vocabulary by being able to construct designs quickly, and co-construct knowledge. During the adaptation and operationalization phases, we suggest ways of combining conventional teaching and learning methods with the variety of features and tools embedded in learning management systems now available. We have studied as a first field of experimentation Moodle platform. We considered the Moodle 2.4 Meta modal proposed in [5] which gathers the entire pedagogical paradigm proposed in this environment.

The remaining of this paper proceeds as follows: section 2 presents the related research works on instructional design for the operationalization of pedagogical scenarios. We focus on ontology based approaches for indexing and conserving the semantics of pedagogical objects and pattern based approaches to express and formalize scenarios; section 3 overviews a case study we conducted to capture needs and constraints about operationalizing pattern-based learning scenarios; section 4 describes our process based on patterns and ontologies to help achieving the automatic operationalization of learning scenarios.

\section{Operationalization of learning situations}

The field of instructional design and technology encompasses the analysis, the design, development, implementation, and evaluation of instructional processes and resources intended to improve learning [27]. Each step is highly affected by the pre- 
vious ones. We are interested in the operationalization of learning scenarios, which converges to the deployment of the designed learning scenarios, intended, or not, for a specific learning environment. In this section, and based on the correlation between designing scenarios and their deployment, we list several approaches expressing learning design knowledge and we emphasize their advantages and weakness in order to get a clearer picture the most suitable and adaptable one to automate operationalizing pattern-based learning scenarios.

Tools are emerging to support a variety of approaches to design learning. In particular, design oriented learning platforms, where teachers-designers create deployable learning scenarios. But this task appears to be complex for one who isn't very well familiarized with learning platforms technologies and computer environments. That's why many research works addressed these learning design issues, but few are those who take into account the aspect of operationalization. As entitled in this paper, we are working specifically on pattern-based designs, and we note that most of these learning design approaches and support tools do not explicitly integrate them in technological learning environment [6]. And when they do, as in Collage [7] case, the intervention of a platform expert is indispensable. This would be justified by the fastidiousness of this step. As a matter of fact, many difficulties and constraints are related to learning platforms, that range from the basic instructional language and rules to the implicit and complex structures related to each particular platform. Thus, these problems will create a semantic gap when considering learning scenarios concepts and platforms features. For example, designing tools based on modeling languages (EML) [8], more specifically the educational standard languages [9] [10] such as CADMOS [11] consider an XML notation, which is judged complex and tends to change the teachers-designers view of their scenarios. Also, since platforms do not follow any educational standards, deploying a standardized scenario would not be easy for a teacher to do. It will require the expertise of a pedagogical engineer. By another way, when those standardized designing tools take the operationalization step into account, it is always about one targeted learning environment (eg: CADMOS generates scripts to only deploy scenarios on Moodle).

As a solution to the lack of expressivity of Educational Modeling Languages, we chose a structured and formalized pattern approach for learning designs. Patterns provide a mean to abstract and represent good practices. They are used to capture expert knowledge of the teaching practice. A pattern is pictured as a three-part structure, specifying a problem and a solution addressing this problem according to a specific context [16]. Defined links between patterns (association, composition, etc.) are considered as a pattern language. [12] proposed a pattern structure and formalization in order to improve the instructional design process, taking advantage of what patterns offer in terms of structure and ease of expression but they do not address their integration into technology enhanced learning (TEL) systems.

Educational language representation was used to help to structure the proposed patterns [13]. We find many projects in the learning design with patterns area, as for example WebCollage [7], a designing tool based on pedagogical patterns. But within this approach, the implementation step still requires a platform expert assistance. [12] Suggests an engineering design process framework and an editing tool based on pat- 
terns, however, the operationalization aspect of the patterns is not addressed. Finally, GLUE!-PS is a tool dealing with deploying learning designs from multiple learning design language/authoring tool to multiple learning environments, yet, the design languages are based on IMS LD, which is too complex for the teachers [15].

We have noticed that most of the proposed design languages and tools do not preserve the semantic meaning of teachers' intention while transposing it on a learning system. There will be a lack of information, and as consequence a need for adapting the initial learning scenario. Moreover, we believe that the use of ontologies for both designing as well as operationalizing scenarios can solve this problem. Ontologies allow having one same semantic base which will retain the essence of the scenario during the transition between learning design and deployment phases. In educational fields, ontologies have played an important role as knowledge representation and sharing mechanism. We find ontologies based on IMS LD language [10], as well as ontologies describing the learning scenario [18] and also ontologies to describe common modules of learning platforms [20]. We noticed that the main advantages of these ontologies take place during the learning design phase. But we highly believe that it would simplify the implementation phase and help us to automate the deployment of patterns based scenarios.

We close this section by noting that the main concern of this work is to study the mechanisms supporting instructional design and scenario's deployment activity by teachers-designers. We are adopting a co-participative and iterative approach with teachers-researchers. The approach is called "Design Based Research" [19], a methodology suitable to both research and design of technology-enhanced learning environments (TELEs). Especially those design experiments involve both scientific and educational values, through scientific processes of discovery, exploration, confirmation, and transmission that create strong links among researching, designing, and engineering. By this approach, we try to reduce the gap between what a technology enhanced learning environment is and how it is defined theoretically (comparing what it is and how it is used in practice).

\section{Deploying a pattern-based learning scenario: Moodle case study}

As pattern-based design approaches have not been studied from the operationalization point of view, we seek through our study to capture the insights of deploying their resulted learning scenarios. We aim at defining a series of constraints to make explicit the structure to follow that would support the automatic operationalization of a pattern-based learning scenario. We also aim to prove the feasibility of automatically import a teacher's point of view of a learning scenario on a computer environment with its embedded language- without losing information.

The research question tackled with this study is: which approaches models and / or techniques to consider for transforming the pattern-based scenarios into implementable models on different learning platforms? 
If we look into the question, it is obvious that we need to explore both the human and the machine sides of a learning scenario. As in figure Fig.1, we defined two starting points:

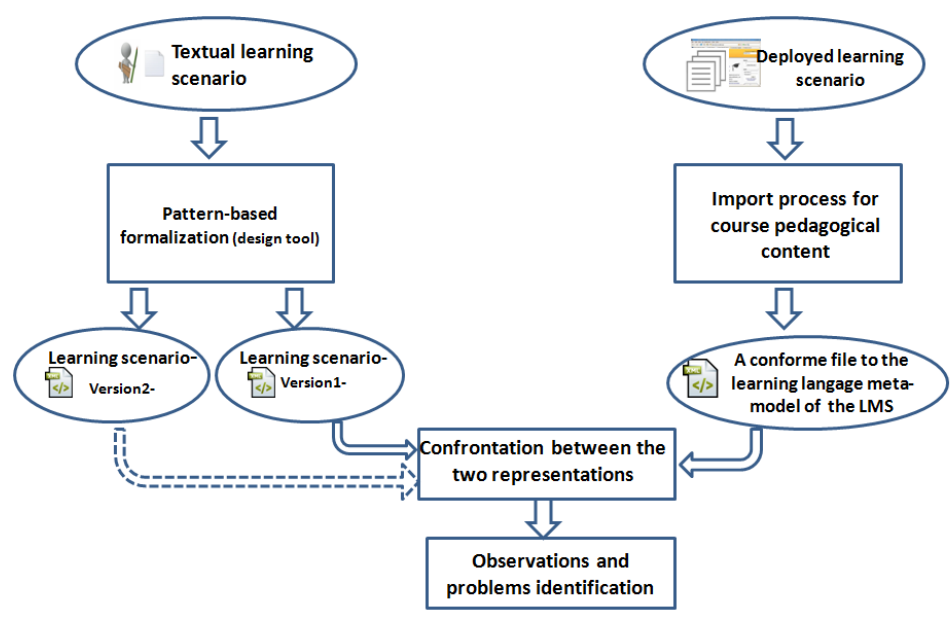

Fig. 1. Case study and methodology

In a first step we considered the textual version of a learning scenario (as intended by the teacher). The study was deployed on an algorithmic introductory course for students in computer science in first university degree (Fig 2). 
Course: Introduction to algorithms and programming.. Strategy: Discover, Remember, Apply, Self assessment. Objectif: At the end of the course the students should be able a problem into sub-problems, also, how to define simple dat Organization: A 5 chapters course: 5 Courses: $1 \mathrm{H} / 10$ Practical se: sessions : $3 \mathrm{H} 00$.

Course Plan: Course 1: Basic elements / Course 2: Basic instructions/ Course cedures and methods / Course 5 : Files

Skills: Technical Design of an IT solution / Development of an IT solution / Te: Cours 1 objectives: To acquire the basic elements to build an algoritl Chapters structure:

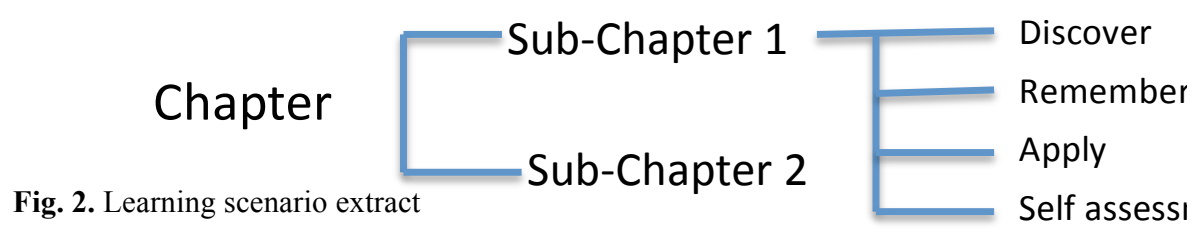

For the need of our study we extracted, during this first step, a list of learning concepts identified in the textual version of our scenario (ex. course plan, role, chapter, pedagogical objective, etc.). We intend to compare this list of concepts with the ones present on the deployed version of the scenario. For this comparison (explained farther in this section), we considered the scenario about the algorithmic course deployed manually on Moodle, which is our platform for experimentation). Then, we modeled this textual version of the teacher's intention using a pattern-based design tool to study the operationalization of the pattern-based design approaches [12]. The environment in which the activities were conceived allows teachers to visually build up learning scenarios (Fig3, Fig.4). As proposed by the tool, the design is not specifically intended to be implemented on a learning platform. The teacher might (or not) desire to create a platform oriented scenario, but the tool only allows him to design it based on 
generic patterns. This was our key to extract the problems that would face this kind of design when it comes to its deployment.

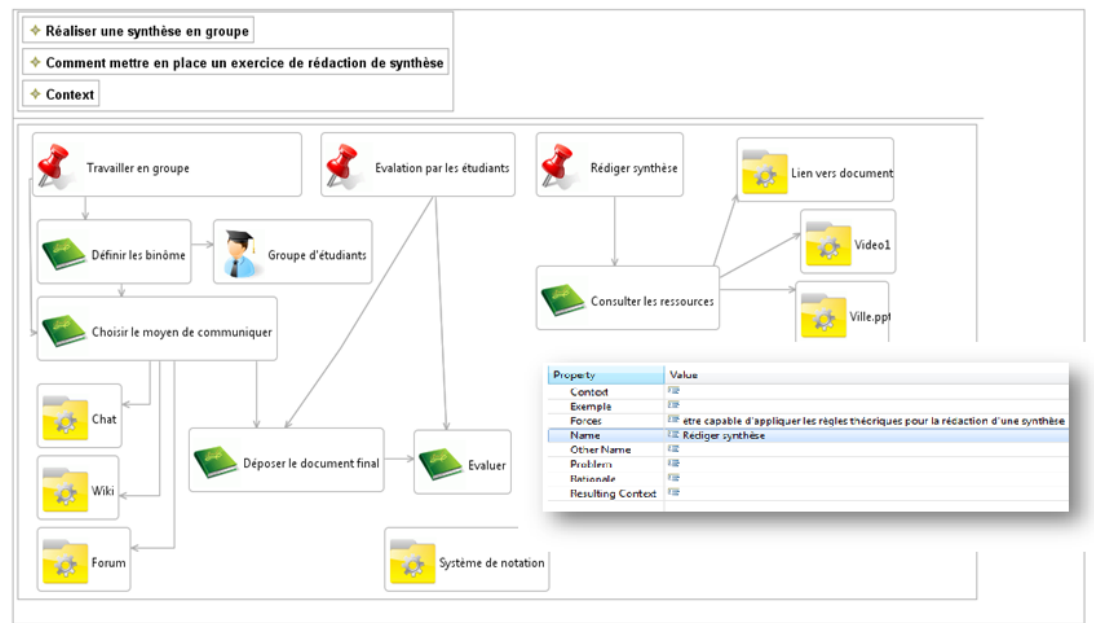

Fig. 3. Learning scenario Version1

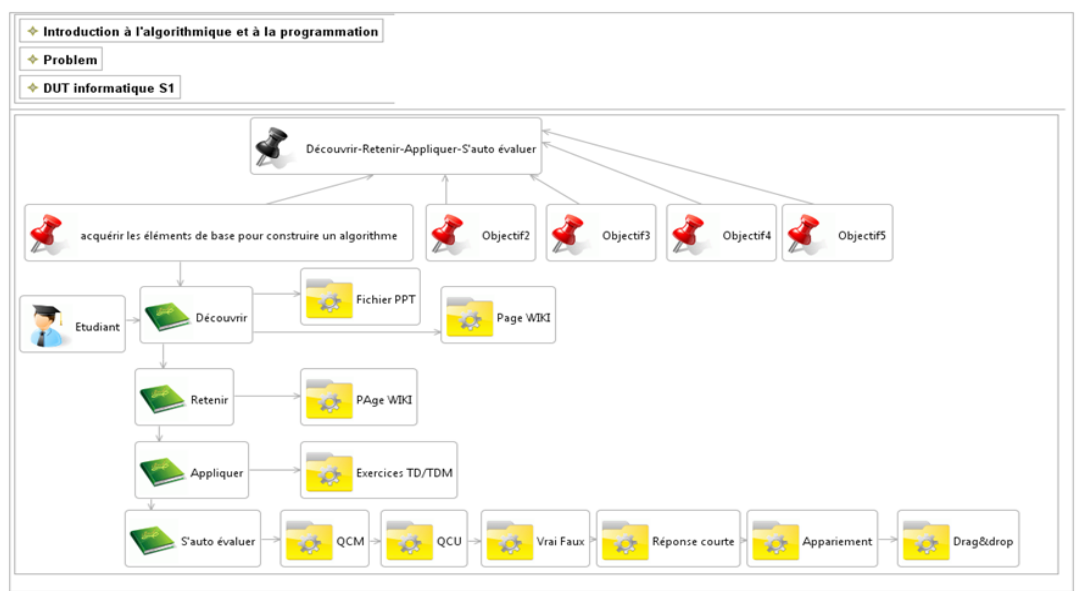

Fig. 4. Learning scenario Version2

We notice that for a textual version of the scenario, several pattern formalizations (without any loss of the learning concepts identified earlier) are possible to be designed. Since it is a pattern based tool, it guarantees the freedom of the teacher's expressiveness. We illustrated the two (but not the only) versions of our learning scenario (Fig3, Fig.4).

After the formalization step, come the observations from an operationalization point of view. We consider the study of Moodle XML files of our scenario (already 
operationalized manually). The idea behind this step is to identify the different needs and constraints around the deployment of learning scenarios on TEL environments. Following the same logic as in the earlier steps, we identified the learning scenario's concepts. Once again, the concepts list remained unchanged (ex. Course plan, role, chapter, pedagogical objective, etc.). This proves us the possibility to reproduce the same human point of view of a learning situation, designed using patterns, on a computer environment. Though, going the other way round (taking into account the deployed scenario and compare its concepts with the ones of the formalized scenario), we have noticed a lack of a set of information needed for the operationalization. We take for example the "Activities completion conditions" which was implemented on the platform but was absent in the formal version of the scenario, teachers didn't pay attention to add the information to their design, even though they are necessary to deploy their scenario.

Those first steps results lead us to conclude that the use of ontologies and metamodeling when defining patterns for scenarios would reduce the semantic gap due to the transformation steps from the teacher's pedagogical intention to the platform.

The third and final step was to confront the XML file obtained from Moodle scenario (after transforming the backup file according to Moodle meta-model [5] ( Fig 5 (2)) with the XML file generated from the pattern-based editing tool ( Fig 5 (1)) (we kept two versions of the learning scenario formalization).

Through this confrontation, we noticed that: a pattern component corresponds, sometimes, to more than one educational concept. The identification is not" unique". We take as an example the Human resource concept "Student", it is defined in two different places: as a Human resource Pattern (and as the "participant" pattern component of the design pattern "Learning situation" (Fig 5). Also, the same pedagogical concepts are identified in different locations for each formalized version (according to the teacher's point of view, if we imagine a new version 3 of the scenario it may be represented in a complete different way). This makes it difficult to automatically implement the scenario on a computer environment. As a conclusion, we say that a pattern-based formalization, considering its semi structured data, may allow teachersdesigners expressing their pedagogical needs without extensive loss of semantic information while representing their pedagogical intention with a pattern-based editing tool. On the other side, this open way of expressivity raises some difficulties for automating the learning scenario operationalization phase. In fact, learning platforms have their own pedagogical structure and language. So, the mapping of each element of the scenario with the relevant concepts in the platform is not obvious. We need to guide the teacher-designer toward a learning design approach that considers the operational needs and constraints, without forcing them to use any specific platform formalism. 


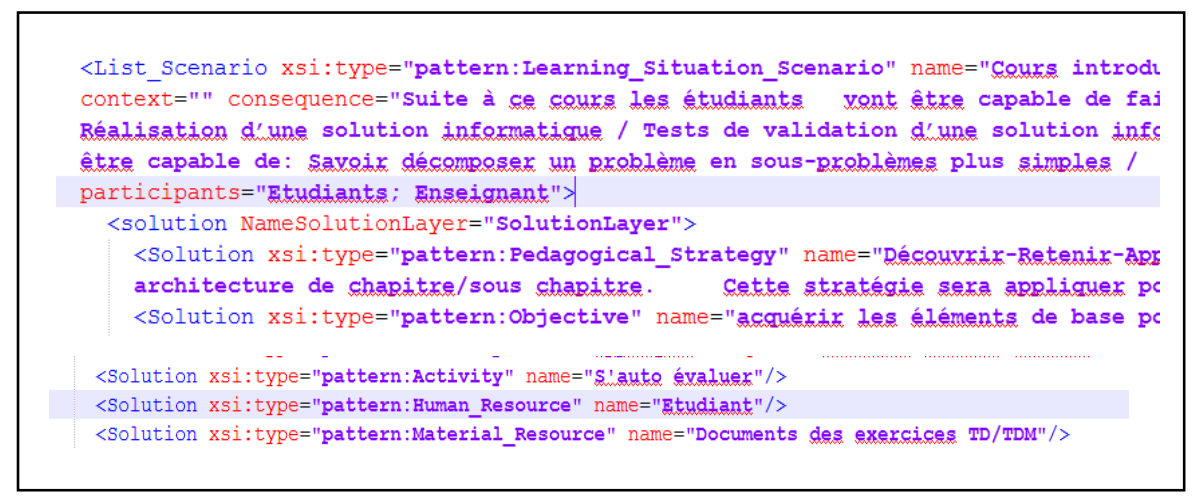

\begin{tabular}{|c|}
\hline $\begin{array}{l}\text { </activityoRressources> } \\
</ \text { section } \\
<\text { section id="18699"> }\end{array}$ \\
\hline 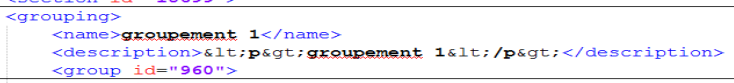 \\
\hline $\begin{array}{l}\text { <group id="961"> } \\
\text { <namerp2</name> } \\
\text { <description }>\text { /description> } \\
\text { </group> }\end{array}$ \\
\hline
\end{tabular}

Fig. 5. XML scenario from the patttern based editor (1) and the platform (2)

Through this study, the previously cited features of a design based on patterns are worth considering for a platform oriented design. The goal is to successfully maintain the semantics of learning scenarios while transforming its pedagogical concepts into learning platforms features. But, we should first point our research on how could we provide to the teacher-designer the predefined components or "patterns", that would be used to gradually build a learning scenario ready to be directly implemented on any learning platform. We must define formalism for these patterns, so that the learning design process delivers a structure helping the automatic operationalization without limiting the degree of expressivity and reuse.

Designing learning scenarios based on patterns is not enough to achieve our automation goal, it is essential for us to combine patterns use with an indexing service. It would help to translate and implement each of the scenario's educational concepts in distinct learning platforms. In this direction, ontologies are also a very important part of this work, considering the knowledge representation and the sharing mechanisms they offer. We model and browse the learning vocabulary and language embedded in our experimental learning platform as well as in learning scenarios. Ontologies allow making a description of learning scenario's context, taking into account the level of granularity used in it (teaching program, course, learning unit, etc.). 


\section{Developing Pattern-based learning designs: A process toward an automatic operationalization}

In this section we describe a five step process as a mean to support learning designers to develop adequate learning designs ready to be directly implemented on a computer environment. We believe that we should offer to teachers a merging of expressivity, but it should be structured enough to make scenarios machine-readable representations of a teaching practice. It is a process where knowledge, competencies, learning activities, resources and delivery modes are pattern-based designed; they are then constructed explicitly in a framework based on our proposed learning scenario ontology. It helps to integrate the teacher's design into an e-learning environment that consists of a number of features and components interacting with learning design (e.g. tests, forums, chats, etc.). Our motto is that information about the computer environment should be added automatically in the learning design. This has the advantage that teachers-designers are not distracted from the problem of designing a learning scenario itself by all the constraints and technical requirements that the learning platforms involve. Let's begin with a general overview of the process: The first two steps structuring (1) and indexing (2) allow a mapping of the educational concepts (coming from the teaching practices and needs of designers) and the learning platforms concepts and features. Formalizing (3), this consists on developing pattern-based scenarios by teachers-designers. Then, we have the step to automate the implementation of scenarios (5). Before that, an adaptation step (4) is conducted to reduce the gap between the pedagogical language embedded in the platforms and the one used by teacher-designers. By the following we give more details about each step:

\subsection{Structuring}

The idea behind this step is to use generic description of a learning scenario as a universal basis to teacher's design. In other words, we have seen in section 3, the need of an ontology modeling the concept of learning scenario. We can observe that the patterns-structured learning design scenarios, for a Moodle application, cause some difficulties while deploying on a computer environment. Some pedagogical concepts, such as "Activity completion condition" or "Activities order" could be missed or ignored. This lack of information prevents the automatic implementation of the scenarios. Based on this observation we propose to identify the different concepts of a learning scenario. The aim is to formalize these concepts in educational patterns (part 4.3). The identification is based on a research work about ontologies and educational standards (see in particular work presented by [17] [20] [21]). To build our namespace, we relied on the definition of a learning scenario and its dimensions to define our basic classes of concepts [22]. We consider different levels of granularity for a learning scenario: a structure unit, an instructional sequence and even an elementary activity (see Fig 6). We used Dublin Core Standard [21], $\mathrm{LOM}^{1}$ and $\mathrm{MLR}^{2}$ to

\footnotetext{
${ }^{1} \mathrm{http} / /$ edutechwiki.unige.ch/en/Learning_Object_Metadata_Standard

${ }^{2} \mathrm{https}$ ://elearningstandards.wordpress.com/tag/mlr/
} 
meet the universal description of the learning vocabulary. We also defined additionnal terms and concepts extracted from our study about learning scenarios [17] [13]. For that, we used $\mathrm{OWL}^{3} / \mathrm{RDF}^{4}$ description as shown in Table 1 . Once the vocabulary for the scenario is built, we proceeded for the classification phase. In order to offer pedagogically correct, significantly related and well structured patterns, we relied on Bloom's taxonomy to classify the educational knowledge and the different types of learning scenarios and activities [14].

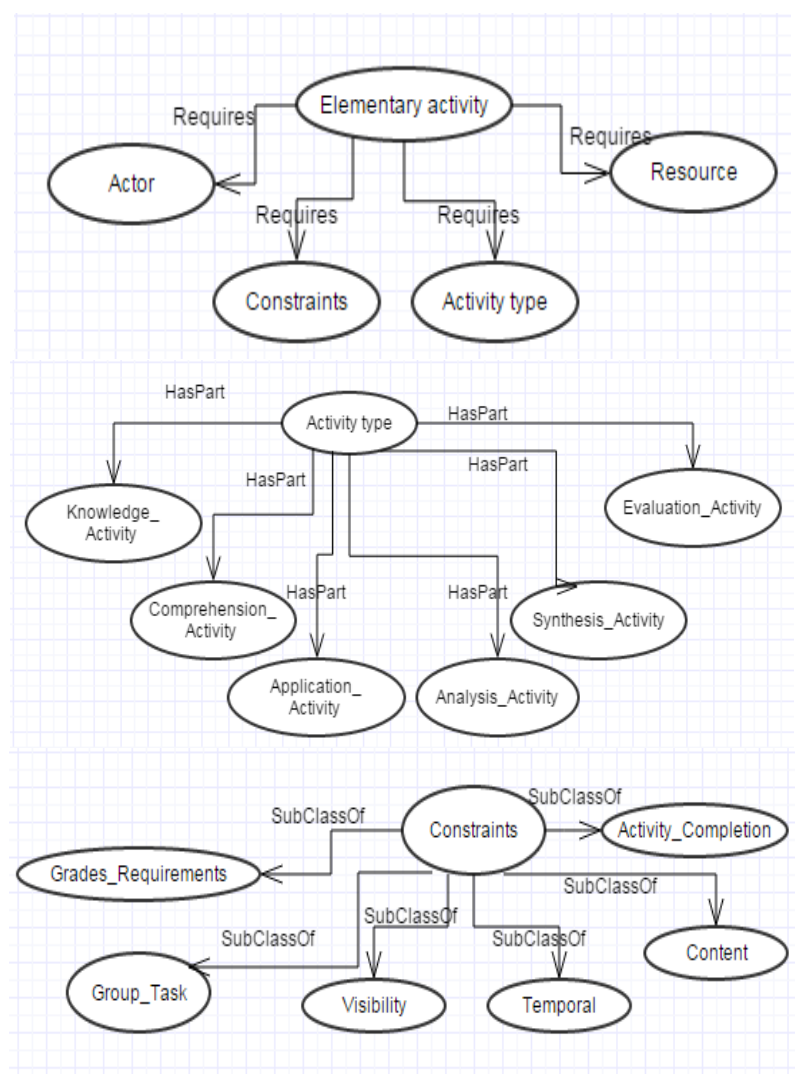

Fig. 6. A sample of our proposed ontology

This classification will help the indexing work (presented next), because the structure of the learning scenario has to satisfy the requirements of its implementation. We are talking about how to ease the detection and extraction of the relevant pedagogical information in order to map it to the most suitable platform feature, having a minimal semantic gap. Semantic relations should be defined between the different levels (Hierarchy, Typology, Compositions, Use etc.). For that

\footnotetext{
${ }^{3} \mathrm{http}: / /$ www.w3.org/2001/sw/wiki/OWL

${ }^{4}$ http://www.w3.org/RDF
} 
we use the "ObjectProperties in OWL description", also, some of the Dublin Core properties that meet our need. We note that as a result of our observations while confronting the two representations of a learning scenario from a platform independent design point of view, and a from a platform deployment one, we defined some constraints that we found obvious to us (Fig.6). These constraints could be completed and ameliorated with the study of multiple versions of the same scenario on different learning environments.

\begin{tabular}{|c|c|c|c|}
\hline Concept & $\begin{array}{l}\text { Type pro- } \\
\text { perties }\end{array}$ & $\begin{array}{c}\text { Object proper- } \\
\text { ties }\end{array}$ & Concept \\
\hline \multirow{6}{*}{$\begin{array}{l}\text { Learning Sce- } \\
\text { nario }\end{array}$} & \multirow[t]{6}{*}{$\begin{array}{l}\text { dct:description } \\
\text { dct:identifier }\end{array}$} & owl:UnionOf & $\begin{array}{l}\text { elementary activity } \\
\text { Activity sequence } \\
\text { Structuration unit }\end{array}$ \\
\hline & & owl: isVersionOf & Learning Scenario \\
\hline & & det: Has & Context \\
\hline & & dct:HasPart & Learning Scenario \\
\hline & & det: source & Pattern \\
\hline & & dct: creator & $\begin{array}{l}\text { Teacher } \\
\text { Designer }\end{array}$ \\
\hline $\begin{array}{c}\text { Structuration } \\
\text { unit }\end{array}$ & $\begin{array}{l}\text { dct:description } \\
\text { dct:identifier }\end{array}$ & dct :hasPart & Activity sequence \\
\hline $\begin{array}{l}\text { Activity se- } \\
\text { quence }\end{array}$ & $\begin{array}{l}\text { dct:description } \\
\text { dct:identifier }\end{array}$ & owl: UnionOf & elementary activity \\
\hline \multirow{4}{*}{$\begin{array}{l}\text { elementary ac- } \\
\text { tivity: }\end{array}$} & \multirow{4}{*}{$\begin{array}{l}\text { dct:description } \\
\text { dct:identifier } \\
\text { dct:Value }\end{array}$} & dct: Requires & Agent \\
\hline & & dct: Requires & Resources \\
\hline & & dct: Requires & Activity Type \\
\hline & & dct: Requires & Constraints \\
\hline Resources & $\begin{array}{l}\text { dct:description } \\
\text { dct:identifier } \\
\text { dct:format }\end{array}$ & dct: Type & Resource_Type \\
\hline \multirow[t]{2}{*}{ DCMI: Agent } & \multirow[t]{2}{*}{$\begin{array}{l}\text { dct:description } \\
\text { dct:identifier }\end{array}$} & det:Mediator & $\begin{array}{l}\text { Teacher } \\
\text { Student }\end{array}$ \\
\hline & & dct:Type & $\begin{array}{c}\text { Group } \\
\text { Individual }\end{array}$ \\
\hline
\end{tabular}

Table 1. A sample of domain vocabulary and its properties.

\subsection{Indexing}

Learning platforms offer features and components usually more suitable for use in a particular pedagogical situation. In this phase of the process, we help teachers to directly find the right equivalent of their design concepts. The idea is the alignment of our proposed ontology concepts with ones on each learning platform. It is a mapping 
between both learning platforms and learning scenarios pedagogical language. For that, we needed to create an ontology for the Moodle platform as a starting point, we intend to study more learning environment to enrich our indexation. The learning platform ontology is built based on its meta-model [5], it was identified through the process of identification and formalization the LMS instructional design language, and we also used the XSD-OWL transformation rules. Through our confrontation work (section 3) between a pattern-based learning scenario and its operationalized version, we identified a component of the learning scenario that has been translated into several features on the learning platform (ex. "Student"). Consequently, we need this indexation as a necessary intermediate phase between the design and the operationalization of a learning scenario. We initially use our ontological description about the learning scenario concepts presented previously (4.1).

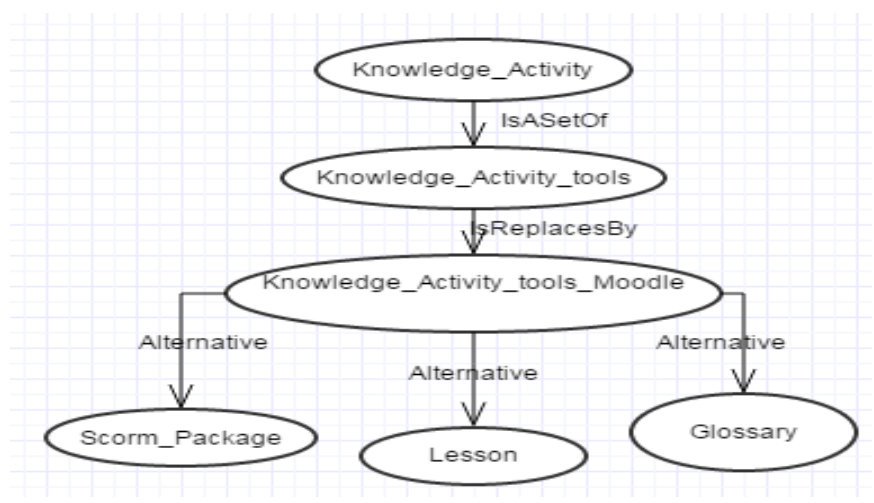

Fig. 7. Indexation example

We proceed on matching every concept, every semantic relation, and every constraint of the learning platform semantic description on our learning scenario ontology. This indexation will create an extension to our ontology (as shown in Fig 7, which is an example of the indexation of a part of Moodle Activities). It is part of the originality of our proposal. Consequently we had a semantic description of Moodle metamodel, reduced to its embedded pedagogical language. The ontology extension allows adapting any set of patterns designed by the teacher-designer, to a directly implemented scenario on any learning platform.

\subsection{Formalizing}

We aim at providing design ideas in a structured way, so that relations between design components are easy to create by teachers and easy to understand by computers. This formalization is the essence of a graphical meta-language for learning design that has an explicit translation to the learning platform pedagogical language using the previously described indexing service. This works in both directions: from visual notation to OWL-XML and from OWL-XML to visual notation. The formalism is mainly inspired by the design patterns that have been adopted in e-learning context 
[23] and the different formalisms used to describe the patterns [24]. The patterns are used to capture best practices and learning design knowledge that relates to ontologies presented in section 4.1 and 4.2 .

This step was proved essential taking into consideration the conclusions we made while modeling our scenarios with the pattern-based editing tool (Part 3). We noticed that it is more likely an open tool for learning design that allows a free expression leading to some difficulties for detecting a specific useful concept. For example, the course duration could be set differently from one version of a scenario to another. Another example as mentioned in part 3, the design of a Role (Student-teacher) isn't quite defined in a unique way, different pattern's components allowed the introduction of such information. Therefore, and in order to get over the automatic operationalization problems, the composition of a pattern, should not compromise the detection of the relevant information, it should be well formalized while offering for teachers some freedom to design their scenarios. To be able to locate any information in a pattern is the key to an automatic operationalization, also, ensured by the use of an ontology allowing combining the pedagogical language concepts of a teacherdesigner and the learning platform concepts (cf section 4.5).

The following illustration Fig. 8 introduces a class diagram to define a learning design pattern classification that we propose. It is inspired from P-sigma's unified formalism [24]. Each Pattern is a set of three components: Header, Core and Resource. Header is the part helping to select patterns; it contains six items as detailed in table 3. Core is the part where the teachers-designers give the solution in terms of modeling activities dealing with their pedagogical intentions. Finally, the Resource part is where the teachers-designers specify the learning object and tools to use. We note that it is a non-obligatory part in the design because sometimes, the need is only to design a flow of activities without any further specification, as in the case of designing a structuration unit, it is only a general definition of a set of objectives and their timeline.

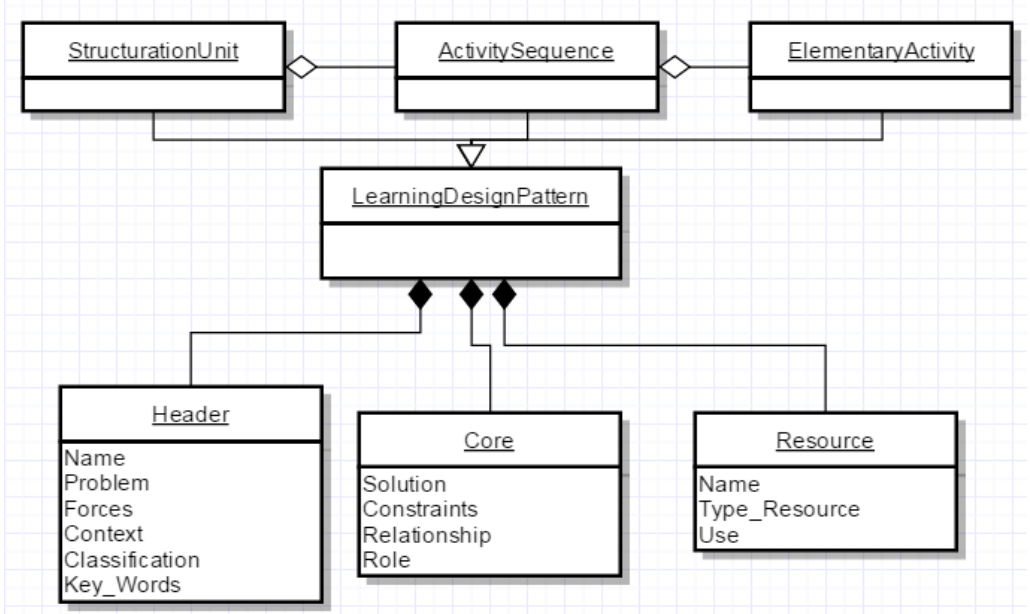

Fig. 8. Learning design pattern's formalism 
In addition to the p-sigma's structure, each of our patterns will be formalized as one of the learning scenario's levels of granularity mentioned in the literature; a learning scenario (LS) can be classified according to different criteria [22]: based on the granularity of the targeted learning situation. We identified three main categories of patterns when examining the main concepts of a scenario: "Structuation unit pattern", "Activity sequence" pattern and "Elementary activity" pattern, we define each type of a learning pattern (Table 2)

\begin{tabular}{|c|c|}
\hline Pattern & \multicolumn{1}{c|}{ Definition } \\
\hline $\begin{array}{c}\text { Structura- } \\
\text { tion unit }\end{array}$ & $\begin{array}{l}\text { It corresponds to a learning situation in which a set of in- } \\
\text { structional sequences are gathered to constitute a logical unit } \\
\text { about a given learning theme and dedicated to a specific } \\
\text { audience. }\end{array}$ \\
\hline $\begin{array}{l}\text { Sequence of } \\
\text { activities }\end{array}$ & $\begin{array}{l}\text { It corresponds to a learning situation where several activi- } \\
\text { ties or sequences are organized in order to reach a learning } \\
\text { goal clearly defined in terms of knowledge and competen- } \\
\text { cies. This organization must be able to express conditions of } \\
\text { sequentiality, optionality and parallelism. It must also des- } \\
\text { cribe the associated data flow process. }\end{array}$ \\
\hline $\begin{array}{l}\text { Elementary } \\
\text { activity }\end{array}$ & $\begin{array}{l}\text { It corresponds to a situation where one or several actors } \\
\text { (lenment for a generally short and contiguous determined } \\
\text { duration. An elementary activity may pursue a precise learn- } \\
\text { ing goal or more simply contribute to the goal associated } \\
\text { with the sequence in which it will be integrated. }\end{array}$ \\
\hline
\end{tabular}

Table 2. Learning design Patterns categories.

The table below describes the different items of a learning pattern; each one of the attributes is proposed after studying the need of balancing between our operationalization's constraints and theories around learning activities and pedagogical experiences (cf section 3). It is very important to note that by filling each of these items, the teacher-designer will create non ambiguous expressions of scenarios, abstract or concrete, that helps their reuse and more importantly, their deployment on a learning platform.

\begin{tabular}{|c|c|c|}
\hline Item & Obligatory & Definition \\
\hline \multicolumn{3}{|r|}{ Header } \\
\hline Name & yes & The name of the pattern. \\
\hline $\begin{array}{c}\text { Problem } \\
\text { (pedagogical objectif) }\end{array}$ & yes & The problem solved by the pattern. \\
\hline $\begin{array}{c}\text { Forces } \\
\text { (pedagogical gain) }\end{array}$ & No & $\begin{array}{l}\text { The pattern contributions through a collection of } \\
\text { quality criteria. }\end{array}$ \\
\hline Contexte & No & The pre-condition of pattern application. \\
\hline Classification & Yes-No & $\begin{array}{l}\text { This item allows distinguishing the pedagogical } \\
\text { classification of each modeled activity. }\end{array}$ \\
\hline
\end{tabular}




\begin{tabular}{|c|c|l|}
\hline Key words & yes & $\begin{array}{l}\text { The mean to provide an intuitive definition of the } \\
\text { pattern's context. }\end{array}$ \\
\hline Core \\
\hline Solution & yes & $\begin{array}{l}\text { The problem solution in terms of a pedagogical } \\
\text { process of activities to follow. (As a graphical } \\
\text { diagram) }\end{array}$ \\
\hline Constraints & No & $\begin{array}{l}\text { The rules necessary for the pattern's implementa- } \\
\text { tion. }\end{array}$ \\
\hline Relationship & yes & $\begin{array}{l}\text { The relation is expressed by an item (or another } \\
\text { pattern) giving a type of link to the pattern de- } \\
\text { scribed. The meaning of each link is based mainly } \\
\text { on the pedagogical intention of the teacher (use, } \\
\text { refine, follow etc.) }\end{array}$ \\
\hline Role & No & $\begin{array}{l}\text { The role defines the actor and the targeted of } \\
\text { each part of the pattern's solution. }\end{array}$ \\
\hline \multicolumn{2}{|c|}{ Resource } \\
\hline Sype of Res- & yes & $\begin{array}{l}\text { The role of a mediated representation of the } \\
\text { learning object. }\end{array}$ \\
\hline Use & yes & $\begin{array}{l}\text { The manner of how the resource is used. (Upload } \\
\text { / download) }\end{array}$ \\
\hline
\end{tabular}

Table 3. Learning design Patterns components.

We chose each item of the proposed patterns' rubrics for their pedagogical contributions. It would be easy for a teacher-designer to define his scenario using his own ideas while translating them on the pattern's components intuitively. We take as an example the "Classification", each designer should be aware of the pedagogical classification of his intended activity: is it a knowledge activity? An evaluation? etc. So, it should not be hard for him to intuitively express his idea of a scenario using our proposed rubrics. As a second illustration, we consider the "context", it is dedicated to explain the pre-conditions, the prerequisites and the elements necessary for the use of the learning scenario based on the pattern, and as consequence we could directly detect the "completion conditions" or "grades constraints" for a deployed learning scenario.

\subsection{Adaptation and operationalizing the pattern-based learning scenario}

This part of the process is described briefly. These two last steps of our process reflect the adjustments to apply on the learning scenario aiming to allow its automatic operationalization. The starting point is the pattern-based learning scenario Fig 9; it should be formalized according to our proposed structure of a deployable patternbased scenario. Depending on the target LMS, we use the module of learning scenario importation [25] to create an instantiation of the indexed concepts (as presented in section 4.3), providing an XML file in accordance with the meta-model of the learning platform. The XSLT transformations are applied to cover the missing information 
and properties if necessary. This importation is automatic and does not require any intervention of the learning platform expert. The teacher only has to express his/her intention and pedagogical need in a semi-open structured language.

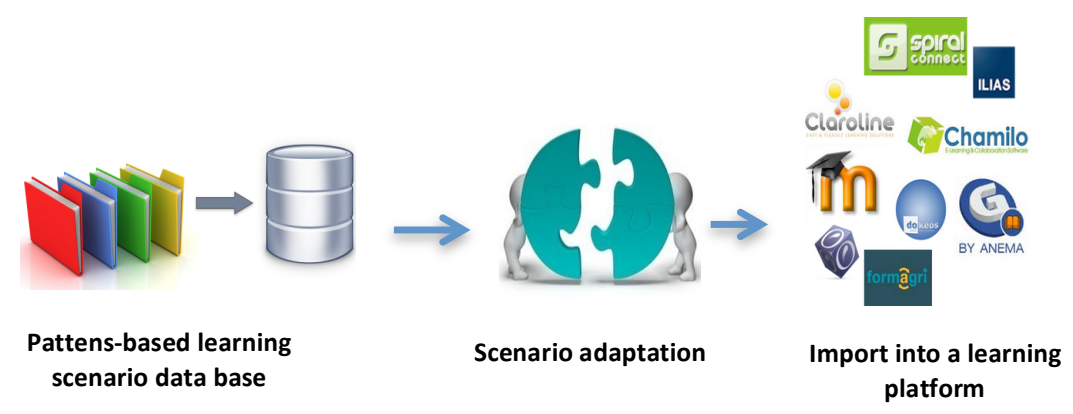

Fig. 9. Adaptation and operationalizing of a learning scenario

\subsection{Data representation}

Considering the data level point of view, the process of operationalization of learning scenarios involved is specified on different levels of representations (from a logical level to the physical level). As shown in the following illustration (Fig 10), we define three levels of representation, depending on our operationalization needs of pattern-based scenarios. 


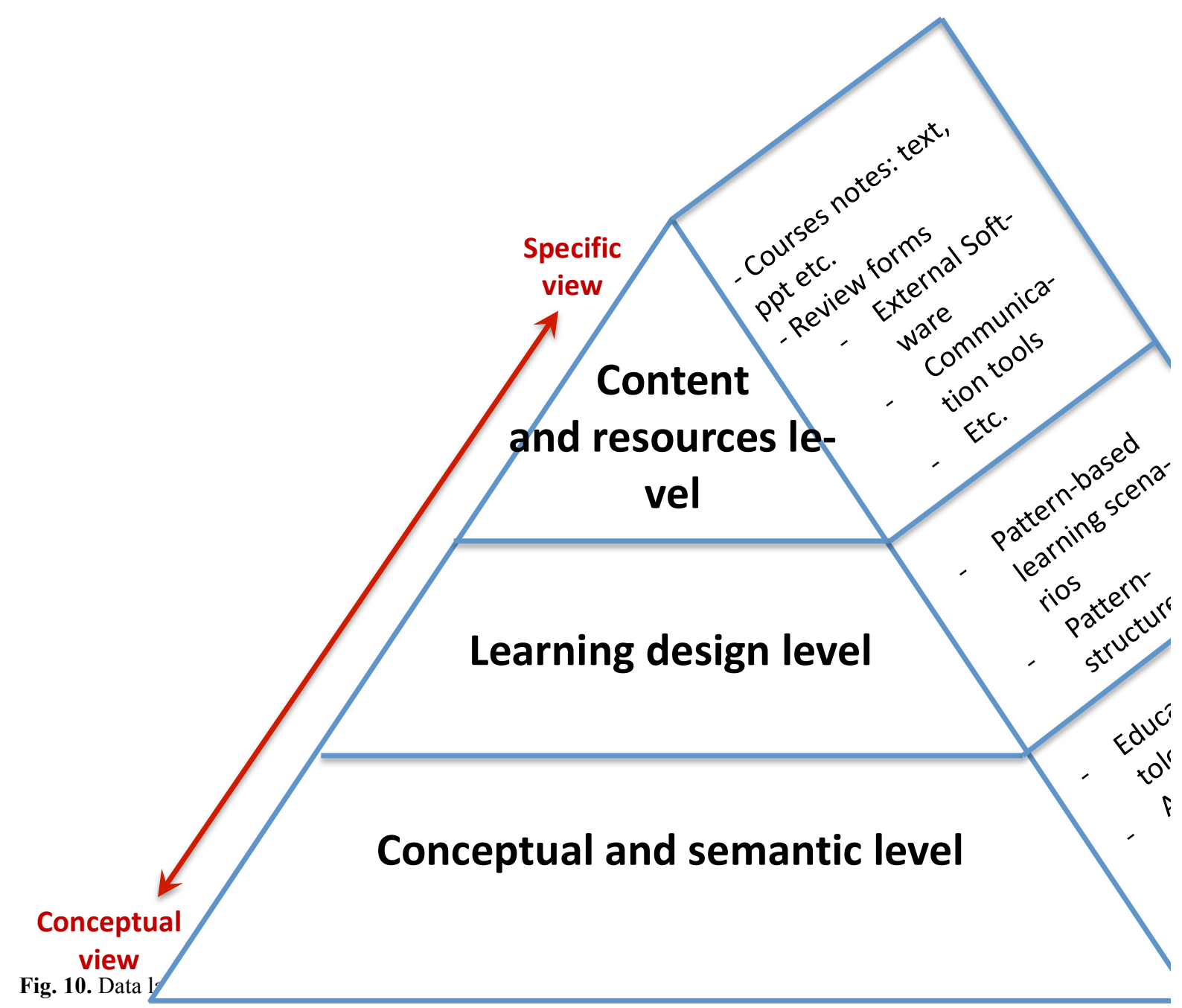

Conceptual and Semantic Level.

This first level of representation stands with the "Computationally Independent" viewpoint, and enables us to have an instructional design knowledge representation as closer as it could be to the language used by a human teacher as well as the language embedded in a learning management system. this layer is about the "Learning scenario" modeled in an ontology inspired. This ontology should reflect the different teaching strategies and the different levels of granularity in a learning scenario (a course, a learning unit etc.). 
Keeping in mind our main objective to automate the operationalization process of learning scenarios, this ontology should include in its definition of concepts, the features provided by the various LMS to consider. This extension is an indexation of the instructional language of a learning platform. Building this semantic level ensures a common vocabulary for all teachers-designers and facilitates the interoperability between different LMS.

\section{Learning / Instructional Design Level.}

The previously presented process's phases "structuring" and "formalizing" provide a representation of the pattern-based scenario. This result is what makes the content of the instructionl design level. Each element of instructional design level is connected to one or more nodes from the semantic representation (level 1).

The elements are linked through "Instructional Relations" that establish the function and identify the various features to use on the learning platform while deploying the scenario.

\section{Content and Resources Level.}

This content layer consists of different learning objects (documents and material resources) used in different contexts such as: course notes, exam's forms, the use of software and any mean of communication etc. A classification of these objects is considered [26] (presentation, practice, simulation, conceptual models, contextual information and representation objects). This level is strongly related to levels 2 and 3 , it allows to instantiate the objects on learning platforms depending on the choice of use of the teacher-designer (as a support resource, mediation, building knowledge or as course application ).

\section{Conclusion}

In this paper, we propose to offer a mean to guide the automatic operationalization of pattern-based learning scenarios. Especially, that it is based on a process that doesn't require from a teacher-designer to master the complicated instructional language of the learning platform. To validate whether this process allow us to meet our needs, a series of further work is planned. The structured ontology and the indexation of learning platforms concepts within this ontology (as proposed in section 4.1 and 4.2) is considered as a data layer representation of our tool's architecture. A service of indexing and adaptation will be developed using Jena ${ }^{5}$ library, which is a free and open source Java framework for building Semantic Web and Linked Data applications. Those services are the business back-end treatment of the teacher's Visual Design based on the proposed patterns. It will help the creation of a machine readable scenario, well adaptable to a target platform and ready to be operationalized without

\footnotetext{
${ }^{5}$ https://jena.apache.org/
} 
any extra effort from the teacher. We relied on a case study that helped us to highlight the problems facing the operationalization of learning scenarios based on patterns. We proved the need to use a semantic description of a learning scenario to minimize the gap between a human instructional language and a machine readable one. Moodle platform was our first application environment; we intend to extend our indexing phase by studying other learning platforms to demonstrate the feasibility of our proposition.

\section{References}

1. Mor, Y., Craft B. \& Hernandez-Leo, D., 2013. The art and science of learning design: Editoral. Research in Learning Technology, Vol.21.

2. Agostinho, S., Bennett, S., Lockyer, L. \& Harper B., 2011. The future of learning design, Learning, Media and Technology, 97-99.

3. Rice, W., 2011. Moodle 2.0 E-Learning Course Development. Packt Publishing Ltd.

4. Sakai, 2015. https://www.sakaiproject.org/

5. Mawas, N. E., Oubahssi, L., \& Laforcade, P., 2015. A meta-model based approach for identifying and formalizing LMS instructional design languages. In Collaboration Technologies and Systems (CTS), 159-166.

6. Chimalakonda, S. \& Nori, K. V., 2014. A Patterns-Based Approach for Modeling Instructional Design and TEL Systems" $14^{\text {th }}$ International Conference on Advanced Learning Technologies, 54-56.

7. Villasclaras-Fernández, E., Hernández-Leo, D., Asensio-Pérez, J. I., \& Dimitriadis, Y., 2013. Web Collage: an implementation of support for assessment design in CSCL macroscripts. Computers \& Education, 79-97.

8. Koper, R., 2001 Modelling Units of Study from a pedagogical perspective: The pedagogical metamodel behind EML. Technical Report OUNL.

9. Martel, C., Vignollet, L., Ferraris, C., David, J. P., \& Lejeune, A., 2006. Modeling collaborative learning activities on e-learning platforms. 707-709.

10. IMS-LD. IMS Learning Design, http://www.imsglobal.org/index.html

11. Katsamani, M., Retalis, S., \& Boloudakis, M., 2012. Designing a Moodle course with the CADMOS learning design tool. Educational Media International, Vol.49(4) 317-331

12. Clayer, J. P., Piau-Toffolon, C., \& Choquet, C., 2014. Assistance for Learning Design Community-A Context-awareness and Pattern-based Approach. In CSEDU, 293-300.

13. Buendía-García, F., \& Benlloch-Dualde, J. V., 2011. Using patterns to design technologyenhanced learning scenarios, eLearning Papers 27 1-12.

14. Anderson, L. W., \& Krathwohl, D. R., 2001 A taxonomy for learning, teaching and assessing: A revision of Bloom's Taxonomy of educational objectives: Complete edition, New York, Longman.

15. Prieto, L. P., Asensio-Pérez, J. I., Dimitriadis, Y., Gómez-Sánchez, E., \& Muñoz-Cristóbal, J. A., 2011. GLUE!-PS: a multi-language architecture and data model to deploy TEL designs to multiple learning environments. InTowards ubiquitous learning. Springer Berlin Heidelberg 285-298.

16. Alexander, C., Ishikawa, S., Silverstein, M., 1977. A pattern language, town, buildings, constructions, Oxford University Press.

17. Abedmouleh, A., Oubahssi, L., Laforcade, P., \& Choquet, C., 2012. An Analysis Process for Identifying and Formalizing LMS Instructional Language. In ICSOFT 218-223. 
18. Paquette, G., 2014. A Competency-Based Ontology for Learning Design Repositories. International Journal

19. Wang F., Hannafin M.J., 2005. Design-based research and Technology-Enhanced Learning. ETR\&D. Vol.53(4) 5-23

20. Montenegro, C., Cueva-Lovelle, J-M., Sanjuán-Martínez, O. Gaona-Garcia, P-A., 2010. Modeling and comparison study of modules in open source lms platforms with cmapstool.

21. LOM specification, Learning Object Metadata, http://tsc.iee.org/wg 12/index.html,

22. Weibel, S., 1998. "Dublin core metadata for resource discovery." Internet Engineering Task Force RFC 2413.222.

23. Pernin, JP., Lejeune,A., 2004. Dispositifs d'apprentissage instrumentés par les technologies : vers une ingénierie centrée sur les scénarios. Technologies de l'Information et de la Connaissance dans l'Enseignement Supérieur et de l'Industrie. Université de Technologie de Compiègne. 407-414.

24. Goodyear, P., Yang, D., 2008 Patterns and pattern languages in educational design. Handbook of research on learning design and learning objects: Issues, applications and technologies 167-187.

25. Conte, A., Fredj, M., Hassine, I., Giraudin, J. P., \& Rieu, D., 2002. "A tool and a formalism to design and apply patterns."Object-Oriented Information Systems. Springer Berlin Heidelberg, 135-146.

26. Churchill, D., 2007.Towards a useful classification of learning objects.Educational Technology Research and Development, Vol.55(5) 479-497.

27. Andrews, D. H., \& Goodson, L. A.,1980. A comparative analysis of models of instructional design. Journal of instructional development, Vol.3 (4), 2-16. 